NBER WORKING PAPER SERIES

\title{
WHY ARE THERE RICH AND POOR COUNTRIES?: SYMMETRY-BREAKING IN THE WORLD ECONOMY
}

Kiminori Matsuyama

NBER Working Paper 5697

\section{NATIONAL BUREAU OF ECONOMIC RESEARCH 1050 Massachusetts Avenue \\ Cambridge, MA 02138}

August 1996

The first draft of this paper was prepared for the TCER-NBER-CEPR Trilateral Conference, "Economics of Agglomeration," Tokyo, Japan, January 11 and 12, 1996. This paper is part of NBER's research program in International Trade and Investment. Any opinions expressed are those of the author and not those of the National Bureau of Economic Research.

(C) 1996 by Kiminori Matsuyama. All rights reserved. Short sections of text, not to exceed two paragraphs, may be quoted without explicit permission provided that full credit, including $\odot$ notice, is given to the source. 


\title{
WHY ARE THERE RICH AND POOR \\ COUNTRIES?: SYMMETRY-BREAKING \\ IN THE WORLD ECONOMY
}

\begin{abstract}
To explain cross-country differences in economic performance, the economics of coordination failures typically portrays each country in a closed economy model with multiple equilibria and then argues that the poor countries are in an equilibrium inferior to those achieved by the rich. This approach cannot tell us anything about the degree of inequality in the world economy. A more satisfactory approach would be to build a world economy model and show why it has to be separated into the rich and the poor regions, i.e., to demonstrate the co-existence of the rich and poor as an inevitable aspect of the world trading system. In the present model, the symmetry-breaking of the world economy into the rich and the poor occurs because international trade causes agglomeration of different economic activities in different regions of the world. International trade thus creates a kind of "pecking order" among nations, and as in a game of "musical chairs," some countries must be excluded from being rich.
\end{abstract}

Kiminori Matsuyama

Department of Economics

Northwestern University

2003 Sheridan Road

Evanston, IL 60208

and NBER

kmatsu@merle.acns.nwu.edu 


\section{Introduction.}

One major challenge for the theory of economic development is to explain the diversity of economic performances across the countries. In short, "Why Are There Rich and Poor Countries?" The economics of coordination failures attempts to answer this question by developing a model of multiple equilibria, and arguing that the Rich countries somehow managed to achieve a Pareto-superior equilibrium, while the Poor countries fail to achieve a necessary coordination and are trapped in a Pareto-inferior equilibrium. The most influential work along this line is Murphy, Shleifer, and Vishny (1989). In the context of imperfectly competitive closed economies with aggregate spillovers, they have demonstrated the coexistence of a good equilibrium and a bad equilibrium. While insightful, it is difficult to see within their framework why some countries have to be trapped in the bad state, while others find themselves in the good state, since the coordination in the good state is no more difficult than in the bad state. Indeed, all the models they developed are static, and taken literally, the economy could go back and forth between the two equilibria. Their paper hence offers no compelling reason why we have observed and continue to observe the huge cross-country differences. (As one commentator said, "according to their theory, in order to eliminate the development problem, all we need to do is simply imitate the Rich countries, and people in the Poor countries are just too dumb to be able to do it.")

One can partially deal with this criticism by making the model dynamic. For example, in a series of papers, I studied dynamic models of development with multiple steady states: Matsuyama (1991, 1992); see also Ciccone and Matsuyama (1996). In these models, the initial condition of the economy plays an important role in determining the eventual state toward which the economy will gravitate 
(without entirely ruling out the possibility of "economic miracles," or "takeoffs", i.e., some countries may occasionally escape from the poverty trap and join the club of the Rich countries). These dynamic models thus help to explain why the cross-country differences could be self-perpetuating and sometimes tend to magnify over time, and, at the same time, they are consistent with a few observations of "economic miracles." Nevertheless, these studies do not explicitly model a mechanism of generating the initial cross-country differences, and hence come short of offering an answer to the question, "Why Are There Rich and Poor Countries?"

In all these studies, each country is modelled a closed economy, an independent, isolated entity. Hence, multiple equilibria suggest merely the possibility of the co-existence of Rich and Poor countries. The models cannot tell us anything about the degree of inequality in the world economy.

This paper is an attempt to answer this question, "Why Are There Rich and Poor Countries?" from a global perspective, although the lessons from the previous studies are also incorporated here. Instead of portraying each country in a close economy model with multiple equilibria, and arguing that different countries are in different equilibria, as the previous studies have done, this paper offers a model of the world economy, where many (inherently) identical countries trade with one another. It is shown that cross-country differences in the standard of living and in the income appear as a stable outcome of international trade. According to this model, the co-existence of Rich and Poor countries is not just the possibility. It is an inevitable aspect of the world trading system.

The model developed below adopts many specific assumptions for the sake of concreteness. Nevertheless, the logic behind the result is fairly general and 
can be understood intuitively. Imagine that there are a list of goods that need to be consumed. Furthermore, there are some agglomeration economies in the production of each of these goods. In the absence of international trade, these goods must all be produced in each country. Without any innate difference across countries, each country produces these goods by the same amount, and there is no cross-country difference. Now introduce the possibility of international trade in these goods. The equilibrium allocation under autarky remains an equilibrium, but such a symmetric allocation can no longer be stable in the presence of agglomeration economies. As different countries start acquiring comparative advantage in different goods, the production of each good concentrates into some countries, which leads to an emergence of a system of the international division of labor. The stable cross-country difference appears as a result of "symmetrybreaking" in the world economy, caused by international trade. And some countries become Rich if they are lucky enough to acquire comparative advantage in goods associated with large agglomeration economies, while other countries, those which happen to acquire comparative advantage in goods with small agglomeration economies, become poor.

From the perspective of an individual country, the problems of Poor countries may look just like those captured in the previous studies. They fail to achieve a necessary coordination to reach a Pareto-superior equilibrium and find themselves in a Pareto-inferior equilibrium. The problems thus seem just a matter of coordination failures. The global perspective, however, offers a different view. The international division of labor requires different countries to take charge of producing different tradeable goods, with differing degrees of agglomeration economies. International trade thus creates a kind of "pecking order" among nations. Not all countries can be Rich: some countries must be 
excluded from being Rich, just like in a game of "musical chairs." At the same time, the model does not rule out the possibility that some (but not all) countries might succeed in overcoming the coordination failures, and becoming Rich. This feature of the model makes it possible to talk about the effects of such an "economic miracle" in the world economy.

Although mainly motivated by the development problem, this paper can also be viewed as a contribution to the literature on North-South trade. The neoclassical trade theory approaches the North-South problem by first assuming that there exist some fundamental differences across the two regions of the world, say in labor productivity or in the factor endowment, and then examining the consequences of trade between the two regions. This approach cannot adequately deal with the concerns held by many "structuralist" or "radical" economists, such as Baran (1957), Myrdal (1957), and most notably Prebisch (1950), who believe that international trade is a cause of the huge differences between the two regions. The approach adopted in this paper explains a separation of the world economy into the Rich and the Poor through "symmetrybreaking," capturing an element of the radical view of the world economy. The present framework thus makes it possible to address the validity of policy recommendations offered by the radical economists in a more formal manner. ${ }^{1}$

The closest to this paper in spirit is the recent work on economic geography by Krugman (1991), which shows that a reduction in transport costs causes a symmetry-breaking to separate the otherwise identical regions into the manufacturing belt and the agricultural hinterland. In this literature, the

\footnotetext{
${ }^{1}$ Matsuyama (1995) discusses more broadly how the notions of "symmetrybreaking," and "pattern formations," borrowed from recent development in nonlinear sciences, can be useful in thinking about a variety of economic issues, which cannot be addressed appropriately within the neoclassical paradigm.
} 
factor mobility plays an important role in generating the agglomeration. To the contrary, the factor mobility plays no role in this paper, which is more relevant in the context of international trade. A simpler version of the model in this paper, and a few of its implications, has been sketched in my recent survey article on complementarities and cumulative processes; Matsuyama (1995, pp.720721). Hence, this paper can be viewed as its elaboration and its extension. In the next section, I lay out the physical structure of the world economy. The building blocks of the model are fairly standard, so that I refrain from discussing specification issues in detail. The purpose of this section is rather to establish the notations, and highlight the key features of the model. In section 3, I discuss the equilibrium allocation under autarky. In section 4, I look at the world economy in equilibrium. In section 5, I discuss some implications of the model. Section 6 concludes.

\section{The Physical Structure of the World Economy.}

The world economy consists of a continuum of identical small countries. Each country is endowed with L units of labor, which is the only primary factor of production. There are three consumption goods, 1, 2, and 3. Good 1 and Good 2 are tradeable, while Good 3 is nontradeable. (Think of them as Agriculture, Manufacturing, and Services.) The representative consumer has Cobb-Douglas preferences over the three goods, which can be represented by an expenditure function, $E=P_{1}^{\beta_{1}} P_{2}^{\beta_{2}} P_{3}^{\beta_{3}} U$, where $U$ is utility, $P_{i}$ the price of good $i$, and $\beta_{i}$ the share of Good $i$ in consumer's expenditure, satisfying $\beta_{1}+\beta_{2}+\beta_{3}=1$. By denoting the aggregate income by $\mathrm{Y}$, the budget constraint is then written as 


$$
Y=P_{1}^{\beta_{1}} P_{2}^{\beta_{2}} P_{3}^{\beta_{3}} U
$$

The assumption of the Cobb-Douglas preferences not only helps to keep the algebra simple, but also implies that both Good 1 and Good 2 (as well as Good 3) are "essential," i.e., there are positive demand for these goods at any $f i n i t e$ prices. This means that the two tradeable goods must always be produced somewhere in the world. This feature plays an important role in the following analysis.

The three consumption goods are produced competitively, with constant returns to scale technologies. All the inputs are nontradeable, and they are labor and a variety of differentiated intermediate inputs, which are aggregated by a symmetric CES production function, as in Dixit and stiglitz. Labor and the composite of intermediate inputs are combined with a Cobb-Douglas technology with $\alpha_{i}$ being the share of intermediates. The unit cost of production in each consumption goods sector can thus be expressed as

$$
C_{1}=W^{1-\alpha_{1}}\left[\int_{0}^{N}[p(z)]^{1-0} d z\right]^{\frac{\alpha_{1}}{1-\sigma}}
$$

where $W$ is the wage rate, $N$ the range of differentiated intermediates available in the marketplace, $\mathbf{p}(\mathbf{z})$ the price of variety $\mathbf{z}$, and $\sigma>1$ the direct partial elasticity of substitution between every pair of intermediates. It is assumed that a different sector relies on the intermediate input sector to a different degree; Sector $i$ spends $\alpha_{i}$ fraction of their revenue on the intermediates. Without much loss of generality, sector 2 is assumed to use intermediate inputs more intensively than sector 1 ;

$$
\boldsymbol{a}_{1}<\boldsymbol{\alpha}_{2}
$$

If Goods 1 and 2 are interpreted as Agriculture and Manufacturing, this intensity 
assumption implies that the production cost of the manufacturing sector depends more heavily upon the local support industries. Needless to say, nothing in the ensuing analysis depends on such an interpretation. What is critical here is that the tradeable goods sectors differ in the degree to which they rely on the local support industries.

The intermediate inputs are supplied by the monopolistically competitive firms. Each variety is supplied by a single firm, which uses ax $(z)+$ f units of labor to produce $x(z)$ units, where $F$ represents the fixed cost. Each firm, aware of its monopoly power, sets the price optimally, but its market power is negligible relative to the aggregate economy, so that each firm does not take into account any strategic interaction with other firms. As is well-known, this specification leads to the following simple pricing rule for each monopolistically competitive firm, $p(z)[1-1 / \sigma]=a w$. By choice of units, one can set $a=1-1 / \sigma$, so as to have $p(z)=p=w$. Hence, the unit cost of production in each sector, given by (2), is simplified to

$$
C_{1}=W N^{\frac{e_{1}}{1-0}}
$$

Hence, in all the consumption goods sector, the production cost declines with $\mathrm{N}$, but the intensity assumption implies that the cost declines faster in sector 2 than sector 1 .

Since all the inputs are priced equally and enter symmetrically in the production functions, all the input producing firms operate at the same scale, $x(z)=x$, and earns the same revenue and the profit. By denoting the revenue of a firm by $S=p x=W x$, its wage bill $B$ and its profit $\Pi$ are expressed as

$$
B=W(a x+F)=\left[1-\frac{1}{0}\right] S+W F
$$


and

$$
\text { II }=S-B=\frac{S}{\sigma}-W F .
$$

respectively.

Finally, there is no barrier to entry or to exit in the intermediate inputs sector, which make all the input producing firms earn zero profit in equilibrium.

\section{The Autarky Equilibrium.}

Although the ultimate goal of the analysis is to examine the world economy, consisting of a continuum of small open economies, let us first look at the equilibrium allocation of each economy in autarky, which offers a useful benchmark for the subsequent analysis.

Because of the Cobb-Douglas preferences, all the consumption goods must be consumed by a positive amount. Hence, in the absence of trade, each economy must produce all the consumption goods, which means that their prices must be equal to their costs: that is, from (4),

$$
P_{I}=C_{1}=W N^{\frac{a_{1}}{1-0}}
$$

Since the representative consumer spends $\beta_{i} Y$ on Good $i$, and sector $i$ spends $100 \alpha_{i}$ of its revenue on intermediate inputs, the total revenue of the inputs sector is

$$
N S=\theta^{A} Y
$$

where

$$
\theta^{A} \equiv \alpha_{1} \beta_{1}+\alpha_{2} \beta_{2}+\alpha_{3} \beta_{3}
$$

represents the share of the intermediates sector in the aggregate income in 
autarky. (Here, superscript A stands for Autarky.) This parameter can also be interpreted as the degree of the aggregate demand externality, measuring the extent to which an increase in the aggregate income generates additional revenue to the monopolistically competitive inputs sector.

Likewise, Sector $i$ spends $100\left(1-\alpha_{i}\right)$ of its revenue on labor, wage income satisfies,

$$
W L=N B+\left[\sum_{1}^{3}\left(1-\alpha_{1}\right) \beta_{1}\right] Y=N\left[\left(1-\frac{1}{\sigma}\right) S+W F\right]+\left[1-\theta_{A}\right] Y
$$

where use has been made of (5) and (9). Combining (8) and (10) yields

$$
\frac{Y}{W}=\left[\frac{\sigma}{\sigma-\theta^{\wedge}}\right][L-N F]
$$

and

$$
\frac{S}{\sigma W}=\left[\frac{\theta^{A}}{\sigma-\theta^{\lambda}}\right]\left[\frac{L}{N}-F\right]
$$

The downward-sloping curve in Figure 1 depicts eq. (12), showing how the revenue of an intermediate input producing firm, $s$, depends on the number of firms, N. In the present model, the profit of each firm declines with its revenue; see eq. (6). This is to say that, given the degree of the aggregate demand externality, $\theta^{A}$, the presence of more firms, and hence that of a wide range of inputs, merely reduces the market size per firm, hence, the profit. Figure 1 thus suggests that a small $N$ implies an excess profit, and a large $N$ implies a loss, and any plausible entry-exit process would lead to the unique intersection, where $\Pi=0$, or $s / \sigma W=F$. Hence, from (12), the variety of intermediate inputs (and the number of firms producing them) is 


$$
N^{A}=\frac{\theta^{A} L}{\sigma F}
$$

in this autarky equilibrium. (Here, superscript A also represents the autarky equilibrium valueg of endogenous variables.) Then, from (7) and (11),

$$
\begin{aligned}
Y^{A} & =W^{A} L \\
\left(P_{i}\right)^{A} & =W^{A}\left[\frac{\theta^{A} L}{\sigma F}\right]^{\frac{a_{1}}{1-\sigma}}
\end{aligned}
$$

and, by inserting (14) and (15) into (1), the utility level in autarky can be derived as

$$
U^{A}=P_{1}^{-\beta_{1}} P_{2}^{-\beta_{2}} P_{3}^{-\beta_{3}} W^{A} L=L\left[\frac{\theta^{A} L}{\sigma F}\right]^{\frac{\theta^{A}}{\sigma-1}}
$$

\section{The World Economy Trading Equilibria.}

Let us now introduce international trade. In the first subsection, I will look at the equilibrium allocations of each small open country, taking the terms of trade exogenously. ${ }^{2}$ Then, in the second subsection, I will look at the equilibrium of the world economy, where the terms of trade are determined endogenously.

\section{4-A. The Small open Economy.}

For each small open economy the relative price of Good 1 and Good $2, q=$ $\mathrm{P}_{1} / \mathrm{P}_{2}$, is exogenously given in the world market. Unlike in autarky, whether the economy produces Good 1 or Good 2 now depends on the ratio of the production cost in the two sectors. From (4), it can be expressed as

\footnotetext{
${ }^{2}$ See Rodríguez-Clare (1993, 1996) and Rodrik (1996) for the analysis of
} similar models of a small open economy. 


$$
\frac{C_{1}}{C_{2}}=N^{\frac{\alpha_{2}-\alpha_{1}}{\sigma-1}}
$$

which increases with $\mathbf{N}$, due to the intensity assumption, (3). This is to say that an economy with a small $\mathbf{N}$ has a comparative advantage in Good 1 (Agriculture), which uses the locally available intermediates less intensively. and an economy with a large $\mathbf{N}$ has a comparative advantage in the intermediate input intensive Good 2 (Manufacturing). The threshold level of $N$, $N(q)$, is determined by the equality, $q=c_{1} / c_{2}$ :

$$
N(q) \equiv q^{\frac{\sigma-1}{\sigma_{2}-\varepsilon_{1}}}
$$

If $N<N(q)$, then the economy produces only two of the three consumption goods, Good 1 and Good 3. By denoting the output of sector 1 by $Q_{1}$, the income identify takes the form, $Y=P_{1} Q_{1}+\beta_{3} Y$, or

$$
P_{1} Q_{1}=\left(1-\beta_{3}\right) Y \text {. }
$$

The total revenue of the inputs sector thus can be written as

$$
N S=\alpha_{1} P_{1} Q_{1}+\alpha_{3} \beta_{3} Y=\theta^{1} Y
$$

where

$$
\theta^{1} \equiv \alpha_{1}\left(\beta_{1}+\beta_{2}\right)+\alpha_{3} \beta_{3}
$$

represents the degree of the aggregate demand externality when $N<N(q)$. (Superscript 1 indicates that, of the two tradeable goods, the economy specializes in Good 1.) Likewise, the wage income can be written as

$$
W L=N B+\left(1-\alpha_{1}\right) P_{1} Q_{1}+\left(1-\alpha_{3}\right) \beta_{3} Y=N\left[\left(1-\frac{1}{\sigma}\right) S+W F\right]+\left(1-\theta^{1}\right) Y .
$$

Solving (18) and (20) simultaneously yields 


$$
\frac{Y}{W}=\left[\frac{\mathbf{0}}{\mathbf{0}-\theta^{2}}\right][L-N F]
$$

and

$$
\frac{S}{\sigma W}=\left[\frac{\theta^{1}}{\sigma-\theta^{1}}\right]\left[\frac{L}{N}-F\right]
$$

A similar analysis can show that, if $N>N(q)$, we have

$$
\frac{Y}{W}=\left[\frac{\sigma}{\sigma-\theta^{2}}\right][L-N F]
$$

and

$$
\frac{S}{\sigma W}=\left[\frac{\theta^{2}}{\sigma-\theta^{2}}\right]\left[\frac{L}{N}-F\right]
$$

where

$$
\theta^{2} \equiv \alpha_{2}\left(\beta_{1}+\beta_{2}\right)+\alpha_{3} \beta_{3}
$$

(Superscript 2 indicates that, of the two tradeable goods, the economy specializes in Good 2.)

In Figure 2, the solid curve depicts how the revenue of a firm depends on the number of firms in the open economy. Equation (22) applies if $N<N(q)$, and eq. (24) if $N>N(q)$, and there is a jump at $N=N(q)$. The revenue function in the autarky case, (12), is also depicted in the figure, by the dotted curve. The relative locations of the two revenue curves reflect the intensity assumption (3), which implies that the three aggregate demand externality parameters, defined in (9), (19), and (25), must satisfy the following inequalities:

$$
\theta^{1}<\theta^{x}<\theta^{2} .
$$

Unlike in the autarky case, the revenue of a firm, and hence its profit, no longer declines monotonically with the number of firms. This is because an 
entry of firms, when it pushes the economy over the threshold level, causes a shift in comparative advantage, which increases the aggregate demand for the intermediate inputs.

Figure 2 is also drawn under the additional condition that the terms of trade, $q=P_{1} / P_{2}$, satisfies

$$
N^{1} \equiv \frac{\theta^{1} L}{\sigma F}<N(q)<\frac{\theta^{2} L}{\sigma F} \equiv N^{2}
$$

or equivalently,

$$
\left[\frac{\theta^{1} L}{\sigma F}\right]^{\frac{\sigma_{2}-\epsilon_{1}}{\sigma-1}} \equiv q^{-}<\frac{P_{1}}{P_{2}}<q^{+} \equiv\left[\frac{\theta^{2} L}{\sigma F}\right]^{\frac{\alpha_{2}-\alpha_{1}}{\sigma-1}} .
$$

(As will be seen later, this condition must hold in the world economy equilibrium, once the terms of trade is endogenized.)

As the figure shows, there are three equilibria, in which the profit is equal to zero; $\mathbf{N}=\mathbf{N}^{1}, \mathbf{N}=\mathbf{N}(\mathrm{q}), \mathbf{N}=\mathbf{N}^{2}$. of thege equilibria, $\mathbf{N}=\mathbf{N}(\mathrm{q})$ is a knife-edge case, where the number of firms is such that the economy's relative cost of production in the two tradeable sectors coincides with the terms of trade. If the economy is slightly below the threshold level, $N(q)$, the economy specializes in Good 1, which makes less use of the local intermediate inputs, and the firms make losses and there is an inducement to exit. If the economy is slightly above the threshold, the economy specializes in Good 2 , which makes greater use of the intermediate inputs, and the firms make profits, which induce more firms to enter. Thus, with a slight perturbation and any plausible entryexit process, this equilibrium would not be observed. The other two equilibria, $\mathbf{N}=\mathbf{N}^{1}$ and $\mathbf{N}=\mathbf{N}^{2}$, are both stable in any plausible entry-exit process in the sense that, if $\mathbf{N}$ is slightly smaller than the equilibrium value, there is an excess entry and hence an incentive to enter, and if $\mathbf{N}$ is slightly larger than 
the equilibrium value, there is a loss and hence an incentive to exit. Under the condition (27), there are two stable equilibria of this economy. ${ }^{3}$

The present model thus predicts that the equilibrium allocations of each country drastically change from the autarky to the open economy case. It is worth pointing out that this change is not caused by a change in the relative price of the two tradeable goods. To see this, note that the relative price is under autarky can be expressed as

$$
\left(\frac{P_{1}}{P_{2}}\right)^{A}=\left[\frac{\theta^{A} L}{\sigma F}\right]^{\frac{\alpha_{1}-\alpha_{2}}{1-\sigma}}
$$

from (7) and (13). Hence, the condition for multiple equilibria in the open economy case, (27), can be rewritten to

$$
\left[\frac{\theta^{1}}{\theta^{\Lambda}}\right]^{\frac{\alpha_{2}-\alpha_{1}}{\sigma-1}}<\frac{P_{1} / P_{2}}{\left(P_{1} / P_{2}\right)^{\lambda}}<\left[\frac{\theta^{2}}{\theta^{\lambda}}\right]^{\frac{a_{2}-\alpha_{1}}{\sigma-1}} .
$$

Note that the lower bound is less than one, while the upper bound is greater than one. Therefore, international trade can cause the drastic change in each country even without affecting the relative price of the tradeable goods.

In what follows, superscript $i=1,2$, is used to distinguish the equilibrium values of endogenous variables, depending on whether $N^{1} N^{1}$ or $N=$ $\mathbf{N}^{2}$. (Subscripts, on the other hand, continue to indicate the goods.) First, note that the economy produces Good $i$ when $\mathbf{N}=\mathbf{N}^{i}$, so that the production cost of Good $i$ must be equal to its price. From (7), this condition pins down the wage rate,

${ }^{3}$ One can also show that, if $N(q) \leq N^{1}$, then $N=N^{2}$ is the unique stable equilibrium and if $\mathbf{N}(q) \geq \mathrm{N}^{2}$, then $\mathrm{N}=\mathrm{N}^{1}$ is the unique stable equilibrium. 


$$
W^{i}=P_{i}\left[\frac{\theta^{1} L}{\sigma F}\right]^{\frac{\alpha_{1}}{\sigma-1}}
$$

Hence,

$$
Y^{1}=W^{1} L=P_{i} L\left[\frac{\theta^{1} L}{\sigma F}\right]^{\frac{a_{1}}{\sigma-1}}
$$

and

$$
\left(P_{3}\right)^{I}=W^{I} N^{\frac{\theta_{3}}{1-\sigma}}=P_{i}\left[\frac{\theta^{1} L}{\sigma F}\right]^{\frac{a_{1}-\alpha_{3}}{\sigma-1}}
$$

By inserting these expressions into (1), the utility of the representative consumer is,

$$
U^{1}=L\left[\frac{P_{1}}{P_{2}}\right]^{\beta_{2}}\left[\frac{\theta^{1} L}{\sigma F}\right]^{\frac{\theta^{1}}{\sigma-1}}=U^{A}\left[\frac{P_{1} / P_{2}}{\left(P_{1} / P_{2}\right)^{\lambda}}\right]^{\beta_{2}}\left[\frac{\theta^{1}}{\theta^{A}}\right]^{\frac{\theta^{2}}{0-1}}
$$

for $\mathbf{N}=\mathbf{N}^{1}$ and

$$
U^{2}=L\left[\frac{P_{2}}{P_{1}}\right]^{\beta_{1}}\left[\frac{\theta^{2} L}{\sigma F}\right]^{\frac{\theta^{2}}{\sigma-1}}=U^{\Lambda}\left[\frac{P_{1} / P_{2}}{\left(P_{1} / P_{2}\right)^{\lambda}}\right]^{-\beta_{1}}\left[\frac{\theta^{2}}{\theta^{\alpha}}\right]^{\frac{\theta^{\alpha}}{\sigma-1}}
$$

for $N=N^{2}$, where use has been made of (16) and (28). Note that a change in the terms of change affects the welfare of the open economy, but its direction depends on the equilibrium. If $\mathbf{N}=\mathrm{N}^{1}$, the economy exports Good 1 , hence an increase in $q=P_{1} / P_{2}$ improves the welfare, while it reduces the welfare if $N=$ $\mathrm{N}^{2}$, that is, when the economy exports Good 2 .

\section{4-B. The World Economy.}

We are now ready to endogenize the terms of trade, $q=P_{1} / P_{2}$, and to look at the world economy as a whole. As shown in the previous section, there are two possible equilibrium allocations for each country: $N=N^{1}$ or $N=N^{2}$. Let $f$ be 
the fraction of the economies, which find themselves in the second equilibrium. For these countries, the relative cost of producing the two tradeable goods is

$$
\left(\frac{C_{1}}{C_{2}}\right)^{2}=\left(N^{2}\right)^{\frac{\varepsilon_{1}-\alpha_{1}}{\sigma-1}}=\left[\frac{\theta^{2} L}{\sigma F}\right]^{\frac{\varepsilon_{2}-\alpha_{1}}{\sigma-1}}=q^{+} .
$$

For the countries at the first equilibrium, it is equal to

$$
\left(\frac{C_{1}}{C_{2}}\right)^{1}=\left[\frac{\theta^{1} L}{\sigma F}\right]^{\frac{a_{2}-\varepsilon_{1}}{\sigma-1}}=q^{-} .
$$

(Recall that $\mathrm{q}^{+}$and $\mathrm{q}^{-}$have been defined in eq. (27).) By arranging the countries along the horizontal axis, first those in the second equilibrium, and then those in the first, these conditions can be depicted by the step function, as shown in Figure 3 .

From the assumed Cobb-Douglas preferences, the relative demand for Good 1 and Good 2 are $D_{1} / D_{2}=\left(\beta_{1} / \beta_{2}\right) /\left(P_{1} / P_{2}\right)$. For the economies with $N=N^{i}$, the output of Good $i$ is given by

$$
\left(Q_{i}\right)^{1}=\frac{\left(1-\beta_{3}\right) Y^{1}}{P_{1}}=\left(1-\beta_{3}\right)\left[\frac{\theta^{1} L}{\sigma F}\right]^{\frac{\sigma_{1}}{\sigma-1}}
$$

(see eq. (17)), while the output of the other tradeable good is zero. Therefore, the world output of Goods 1 and 2 are

$$
\left(Q_{1}\right) N=\left(1-\beta_{3}\right) L\left[\frac{\theta^{1} L}{\sigma F}\right]^{\frac{a_{1}}{\sigma-1}}(1-f),
$$

and

$$
\left(Q_{2}\right)=\left(1-\beta_{3}\right) L\left[\frac{\theta^{2} L}{\sigma F}\right]^{\frac{\sigma_{2}}{\sigma-1}} f,
$$

respectively. Hence, the terms of trade must satisfy 


$$
\frac{P_{1}}{P_{2}}=\frac{\beta_{1}}{\beta_{2}} \frac{D_{2}}{D_{1}}=\frac{\left[\frac{\theta^{2} L}{\sigma F}\right]^{\frac{\alpha_{2}}{\sigma-1}}}{\left[\frac{\theta^{1} L}{\sigma F}\right]^{\frac{a_{1}}{\sigma-1}}}\left[\frac{f}{1-f}\right] \equiv \Phi(f)
$$

which is depicted in Figure 3 as an upward-sloping curve.

At the intersection of the two curves, the relative price of Good $1, q^{\star}$, is smaller than its relative production cost for the $f$ * fraction of the economies, hence these economies specialize in Good 2 , while $q^{*}$ is greater than the relative production cost in the rest of the world economy, which specializes in Good 1. The intersection, $\left(f^{*}, q^{*}\right)$, thus depicts an equilibrium of the world economy. ${ }^{4}$

It is easy to see that the equilibrium of the world economy is not unique. Any point on the upward sloping curve $\Phi(f)$ between $f^{-}<f<f^{+}$is also consistent with the equilibrium conditions. Hence, this model admits a cortinuum of equilibria, with the associated range of equilibrium values

$$
\frac{\left[\theta^{1} / \theta^{2}\right]^{\frac{a_{2}}{\sigma-1}}}{1+\left[\theta^{1} / \theta^{2}\right]^{\frac{a_{2}}{\sigma-1}}} \equiv f^{-}<f<f^{+} \equiv \frac{\left[\theta^{1} / \theta^{2}\right]^{\frac{a_{1}}{\sigma-1}}}{1+\left[\theta^{1} / \theta^{2}\right]^{\frac{a_{2}}{\sigma-1}}},
$$

and

$$
\left[\frac{\theta^{1} L}{\sigma F}\right]^{\frac{\alpha_{2}-\Phi_{1}}{\sigma-1}}=q^{-}=\Phi\left(f^{-}\right)<q=\Phi(f)<q^{+}=\Phi\left(f^{+}\right)=\left[\frac{\theta^{2} L}{\sigma F}\right]^{\frac{a_{2}-\alpha_{1}}{\sigma-1}} .
$$

which is exactly the condition (27), imposed when drawing Figure 2 . Hence, Figure 2 portrays the situation faced by each economy in a world economy equilibrium.

${ }^{4} \mathrm{~A}$ similar geometrical representation of the equilibrium is used in Yanagawa (1996) in his model of a world economy with a continuum of countries. 


\section{Discussions.}

Despite a plethora of equilibrium, indexed by $f \in\left[f^{-}, f^{+}\right]$, the equilibrium conditions impose such strong restrictions on possible allocations that the model is rich in its implications, which will be discussed in this section.

\section{5-A. Cross-Country Comparisons.}

One major implication of the model, indeed the main purpose of building this model, is that, without any innate differences across the countries, some countries (at least $1-\mathrm{f}^{+}$fraction of the world economy) must be in the first equilibrium and others (at least $\mathrm{f}^{-}$fraction) must be in the second equilibrium. The model thus offers a theory of endogenous variations across the countries; two different types of economies must co-exist in the world economy. Therefore, it makes sense to talk about cross-country comparisons.

First, let us look at the differences in their standard of living. From (27), (33), and (34), one can easily show that

$$
\left[\frac{\theta^{1}}{\theta^{2}}\right]^{\frac{\theta^{2}}{\sigma-1}}<\frac{U^{1}}{U^{2}}<\left[\frac{\theta^{1}}{\theta^{2}}\right]^{\frac{\theta^{1}}{\theta-1}}<1 .
$$

Thus, those economies which end up specializing in Good 2 take the greater advantage of the aggregate demand externality, and thereby achieve the higher standard-of-living, than those specializing in Good 1 . Hence, the model predicts an endogenous separation of the world economy into "Rich" and "Poor" countries. This is also true when looking at the factor price and income 
differences. ${ }^{5}$ From (27) and (30), or (31), the range for the relative wages and incomes across the two parts of the world is given by

$$
\left[\frac{\theta^{1}}{\theta^{2}}\right]^{a_{2}}<\frac{Y^{1}}{Y^{2}}=\frac{W^{1}}{W^{2}}<\left[\frac{\theta^{1}}{\theta^{2}}\right]^{a_{1}}<1,
$$

One of the classical problems of development economics is "Why Are Services Cheaper in the Poor Countries?" Many studies, including Balassa (1964), Samuelson (1964), Kravis and Lipsey (1983), Bhagwati (1984), and Panagariya (1988), have addressed this issue, but they all started from some exogenously postulated differences across the Rich and Poor regions. Although no innate difference across the countries is assumed, the world economy equilibrium in the present model can explain the correlation of price levels and the income level across the countries, by looking at the cross-country difference of the price of Good 3, interpreted as services. From (27) and (32),

$$
\left[\frac{\theta^{1}}{\theta^{2}}\right]^{\frac{\alpha_{2}-\alpha_{3}}{\theta-1}} \leq \frac{\left(P_{3}\right)^{1}}{\left(P_{3}\right)^{2}} \leq\left[\frac{\theta^{1}}{\theta^{2}}\right]^{\frac{a_{1}-\alpha_{3}}{\sigma-1}}
$$

Thus, if $\alpha_{1}>\alpha_{3}$, i.e., the service sector is the most labor intensive, then the Services are cheaper in the Poor countries.

\section{5-B. The Welfare Effects of Trade.}

The mere fact that international trade made some countries poorer than others does not necessarily imply that trade made them poorer than before. To answer this, we must compare the utility levels before and after the trade. From

\footnotetext{
${ }^{5}$ Although the factor mobility plays no role in creating the cross-country differences in this model, introducing a mobile factor might be an interesting extension of the model. For example, suppose that there are two factors, immobile labor $L$, and mobile capital $K$, which jointly forms a "generalized factor, " $\mathrm{Z}=\mathrm{F}(\mathrm{K}, \mathrm{L})$. If the restriction of capital mobility is imposed, then the present model can be directly applied by reinterpreted by replacing $L$ by $Z$. Then, if we allow capital to move, then capital flows from the poor to the Rich, which offers an answer to the question posed by Lucas (1990). And the resulting capital outflow magnifies the wage difference across the two regions.
} 
(29), (33), and (34),

$$
\left[\frac{\theta^{1}}{\theta^{\Lambda}}\right]^{\frac{\theta^{\mu}}{\theta-1}}<\frac{U^{1}}{U^{\Lambda}}<\left[\frac{\theta^{2}}{\theta^{\Lambda}}\right]^{\frac{\theta^{\Lambda}-\theta^{1}}{\sigma-1}}\left[\frac{\theta^{1}}{\theta^{\Lambda}}\right]^{\frac{\theta^{1}}{\theta-1}}
$$

and

$$
1<\left[\frac{\theta^{2}}{\theta^{A}}\right]^{\frac{\theta^{A}}{\sigma-1}}<\frac{U^{2}}{U^{A}}<\left[\frac{\theta^{1}}{\theta^{A}}\right]^{\frac{\theta^{A}-\theta^{2}}{\sigma-1}}\left[\frac{\theta^{2}}{\theta^{\Lambda}}\right]^{\frac{\theta^{2}}{\sigma-1}},
$$

Thus, the Rich countries unambiguously have benefitted from trade. For the Poor countries, the lower bound on $\mathrm{U}^{1} / \mathrm{U}^{\mathrm{A}}$ is less than one, hence it is possible that they may have lost from trade. However, the upper bound may be greater than one, so that the Poor may have also benefitted from trade. ${ }^{6}$ This is because there are offsetting gains from specialization, despite the Poor have lost some benefits of the aggregate demand externality, captured by the change in its parameter from $\theta^{\mathbb{A}}$ to $\theta^{1}$. One necessary (but not a sufficient) condition for the Poor to gain from trade is that the terms of trade move in their favor, relative to the autarky: if the relative price remains at the same level with the autarky, $\mathrm{U}^{1} / \mathrm{U}^{\mathrm{A}}<1$, as should be clear from (33).

5-C. The Effects of Development Strategies: An Individual Country Perspective. Regardless of whether the Poor countries have gained or lost from international trade, it is certainly in their interest to switch from the bad equilibrium to the good one and to become Rich. The natural question to ask is what the government of a Poor country can do to facilitate such a transition.

Recall that Figure 2 captures the situation faced by each country. The Poor countries, trapped in the bad equilibrium, suffer from the coordination

${ }^{6}$ For example, if $\alpha_{1}=0.2, \alpha_{2}=0.8, \alpha_{3}=0.1, \beta_{1}=0.6, \beta_{2}=0.2$, and $\beta_{3}=$ 0.2 , then $\theta^{1}=0.18, \theta^{2}=0.66$, and $\theta^{\mathrm{A}}=0.3$, and the upper bound is $(1.04544)^{0.06 /(\sigma-1)}$. 
failures. Among a list of prescriptions commonly offered in the economics of the coordination failure, the least interventionist approach is for the government to direct a coordinated entry of the intermediate input producing firms, through some sorts of "indicative planning." The announcement of a government guideline may help the private sector to coordinate their expectations, thereby succeeding in reaching a better equilibrium. In Matsuyama (1992), I have argued, in the context of the Murphy-Shleifer-Vishny model, that the effectiveness of such a policy announcement depends, among other things, on the gap between the bad equilibrium and the threshold level. The same argument can be applied here. (Indeed, Matsui and Matsuyama (1995) discuss the logic in an abstract game of coordination.) Hence, the government may also want to combine such an announcement with a more interventionist policy to narrow the gap between $\mathrm{N}^{2}$ and $N(q)$. For example, imposing the import tariff on Good 2, taxing sector 1 or subsidizing sector 2 could lower the threshold level in this model, which makes it easier to create a coordinated entry of the firms. In the extreme, the intervention can reduce $N(q)$ to such an extent that $N(q)<N^{1}$, which eliminate the bad equilibrium. The only equilibrium is then $N=N^{2}$. (Rodrik (1996) argues that the secret of East Asian miracles can explained along this line.)

As a more direct measure, a temporary autarky may work. If $\mathrm{N}^{\mathbb{A}}>\mathrm{N}(\mathrm{g})$, then the autarky policy generates a sufficient industrial base, which helps the economy to move toward the better equilibrium when the government removes the trade barriers.

5-D. The Effects of Development Strategies: A Global Perspective.

In 5-C, I have discussed a few policy options the government might want to take in order to facilitate successful development, from the perspective of an 
individual country. These policies cannot make all the countries rich, but may work for some countries. Although the model is silent about which countries can succeed, it is useful for thinking about the possible spillover effects of such an "economic miracle."

To simplify the argument, I will assume that, once some countries succeeded in moving from the bad equilibrium to the good equilibrium, they remove all the interventions that helped them become Rich. As more countries manage to join the club of the Rich countries, $f$ increases along the upward-sloping curve in Figure 3. As a result, $q$ goes up and the terms of trade move in favor of the countries, which remain Poor. On the other hand, the terms of trade deteriorates for the Rich countries. Hence, successful developments of some countries, while a Pareto-improving move from their viewpoint, are not Pareto-improving from the viewpoint of the world economy.

Furthermore, the terms of trade effect of such an "economic miracle" on the countries who remain Poor may be a mixed blessing. As an improvement in their terms of trade, the Poor countries benefit from an increase in $q$, provided that they remain Poor. However, an increase in $q$, by raising the threshold level of development, $\mathbf{N}(\mathrm{q})$, makes their chance of a successful development smaller. As discussed above, the effectiveness of the government announcement to direct a coordination among the private firms harder as the gap between $\mathrm{N}^{1}$ and $\mathrm{N}(\mathrm{q})$ grows The bigger gap also implies that a bigger intervention is required to eliminate the bad equilibrium. Furthermore, an increase in $q$ could lead to $N^{\mathbb{A}}<N(q)$, so that the return to the temporary autarky may no longer generate a sufficient industry base, when the economy removes the trade barriers. In summary, a successful industrialization in some countries, and more generally the presence of early industrializers, may help the Poor agricultural producers by causing a 
favorable terms of trade change, and yet makes it harder for them to follow. In the extreme case, after $f^{+}$fraction of the world economy finished industrializing, it is no longer possible for the remaining countries to become Rich (without impoverishing the currently Rich countries.)

Hence, the present model captures the view of the world held by many radical economists, who believe that the world trading system keeps the South poor at the expense of the earlier industrializers in the North. Some of them even argued in the past that the southern countries could develop only if they severed the link with the established North, and formed their own economic union among them. (This was the idea behind some ill-fated common market agreements in Latin American in the sixties.) The model applies equally to any subgroup of the countries that choose to trade only among themselves. So, if a group of equally Poor countries forms their own trade union and isolates from the rest of the world, it would also separate into the Rich and the Poor countries through a symmetry-breaking. Those unlucky enough to remain poor may hence be disappointed and choose to drop out of the union. ${ }^{7}$

\section{Concluding Remarks.}

Models with multiple equilibria are the most natural framework for explaining the diversity. In a model with unique equilibrium, any attempt to explain the variations of per capita income across regions forces us to introduce variations in other variables, such as saving rates and education, as is commonly

'In the present model, whether the poorer countries in the union want to drop out of the union depends solely on the terms of trade prevailing inside and outside of the union. One can modify the model, such as adding monopolistic competitive tradeable goods, so that there exist some benefits of trading in a larger world. Then, when countries became poorer in the union, they have an incentive to drop out of the union, because, if they had to be poorer, they would rather be poorer in a larger trading community. 
done in growth accounting exercises. Yet the variations in these variables themselves are left unexplained, or need to be explained by introducing variations in another set of variables. This is not to deny the importance of growth accounting exercises, as a useful way of summarizing the correlations of key variables across the regions. But, it tells us little about why poor countries remain poor, because of the simultaneity of the key variables. On the other hand, the economics of coordination failures, as a model with multiple equilibria, can explain the diversity across economies without assuming inherent differences, and hence they serve as a theory of endogenous inequality.

One major drawback of models with multiple equilibria, as the critic might argue, is that they often seem to allow so many possibilities on the equilibrium behaviors, and hence have little predictive content. The previous work on coordination failures in the area of economic development is subject to such a criticism. In these studies, each country is modelled independently, as an isolated entity. Hence, multiple equilibria merely suggest the possibility of the co-existence of Rich and Poor countries; the models do not tell us anything about the degree of inequality in the world economy. This paper, by developing a model of the world economy, explained the inequality as an inevitable aspect of the world trading system, derived some predictions concerning the crosscountry differences, and thereby offered different implications for the way we think of trade and development and the inequalities among nations. 
References :

Balassa, Bela, "The Purchasing Power Parity Doctrine: A Reappraisal, " Journal of Political Economy, December 1964，72, 584-596.

Baran, Paul A. The Political Economy of Growth, Monthly Review Press, 1957.

Bhagwati, Jagdish, "Why Are Services Cheaper in the Poor Countries?" Economic Journal June 1984, 94, 279-286.

Ciccone, Antonio, and Kiminori Matsuyama, "start-up Costs and Pecuniary Externalities as Barriers to Economic Development, " Journal of Development Economics 49 (April 1996): 3-32.

Kravis, Irving, and Robert Lipsey, Towards an Explanation of National Price Levels, Princeton Studies in International Finance, No. 52, November 1983.

Krugman, Paul R. Geography and trade, Cambridge: The MIT Press, 1991.

Lucas, Robert E. Jr., "Why Doesn't Capital Flow from Rich to Poor Countries?" American Economic Review 80 (May 1990): $92-96$.

Matsui, Akihiko, and Kiminori Matsuyama, "An Approach to Equilibrium Selection," with Akihiko Matsui, Journal of Economic Theory 65 (April 1995): 415-434.

Matsuyama, Kiminori. "Increasing Returns, Industrialization, and Indeterminacy of Equilibrium," Quarterly Journal of Economics, May 1991, 106 (2), 617-50.

Matsuyama, Kiminori. "The Market Size, Entrepreneurship, and the Big Push," Journal of the Japanese and International Economies, December 1992, $\underline{6}(4)$, 347-64.

Matsuyama, Kiminori. "Complementarities and Cumulative Processes in the Models of Monopolistic Competition," Journal of Economic Literature, June 1995, $33,701-729$.

Matsuyama, Kiminori. "Comments on Paul Krugman's 'Complexity and Emergent Structure in the International Economy' "in Alan V. Deardorff, James A. Levinsohn, and Robert M. stern, eds., New Directions in Trade Theory, Ann Arbor: University of Michigan Press, 1995.

Murphy, Kevin; Andrei Shleifer, and Robert Vishny, "Industrialization and the Big Push," Journal of Political Economy, October 1989, 97 (5), 1003-26.

Myrdal, Gunnar. Economic theory and under-developed regions, London: Duckworth, 1957.

Panagariya, A. "A Theoretical Explanation of Some styled Facts of Economic Growth," Quarterly Journal of Economics August 1988, 103 (3) ,509-526.

Prebisch, Raul. Economic Development of Latin America and Its Principal Problems, The Economic Commission for Latin America, United Nations, 1950.

Rodríguez-Clare, Andres. The Division of Labor, Agglomeration Economies, and Economic Development, Ph.D. dissertation, Stanford University, 1993.

Rodríguez-Clare, Andres. "The Division of Labor, and Economic Development," Journal of Development Economics 49 (April 1996) : 3-32.

Rodrik, Dani. "Coordination Failures and Government Policy in Intermediate Economies: A Model with Applications to East Asia and Eastern Europe," Journal of International Economics, 40 (February 1996): 1-22.

Samuelson, Paul, "Theoretical Notes on Trade Problems," Review of Economics and statigtics May 1964, 46, 145-154.

Yanagawa, Noriyuki, "Economic Development in a World with Many Countries," Journal of Development Economics 49 (May 1996): 271-288. 


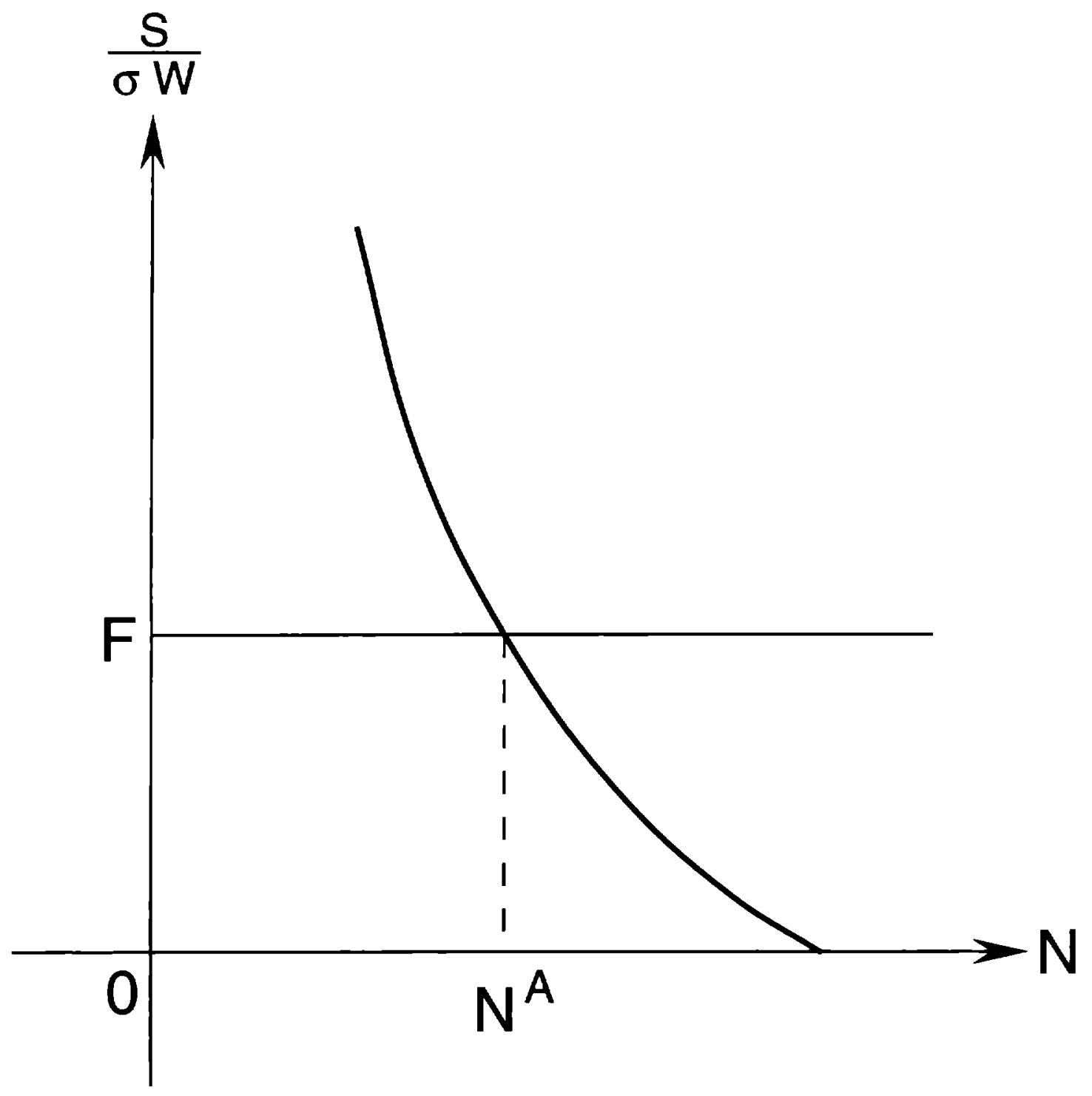

Fig. 1 


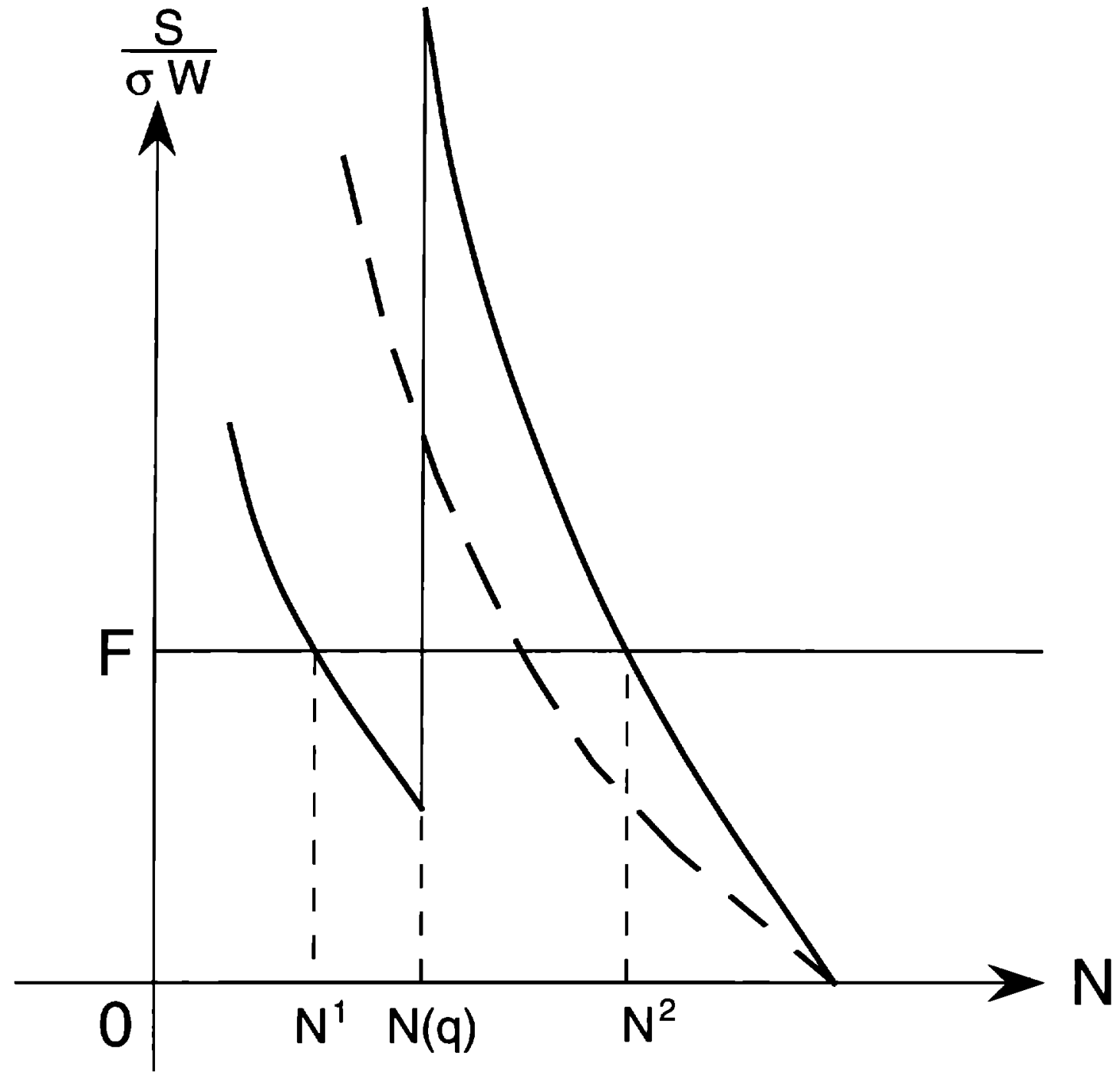

Fig. 2 


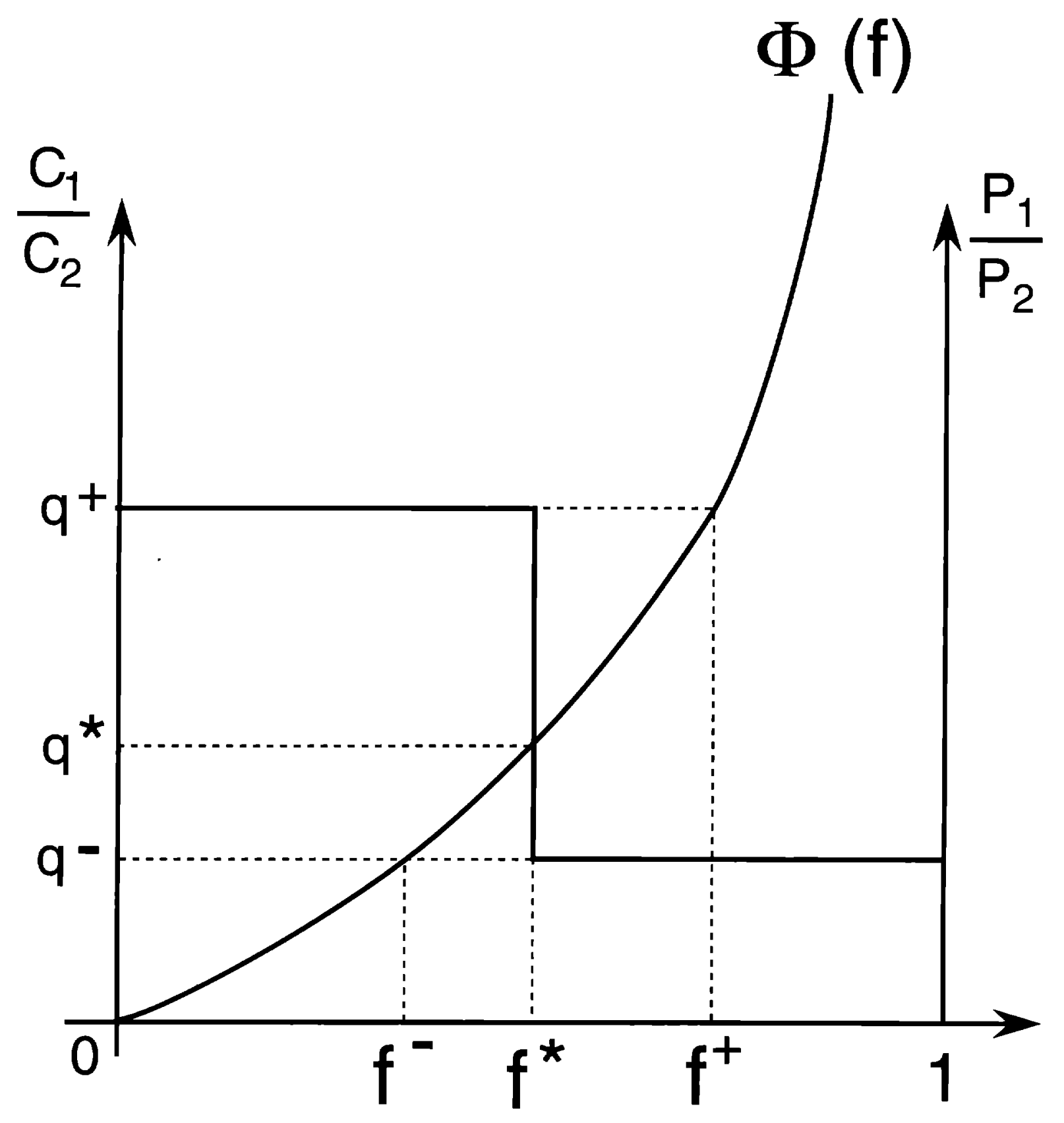

Fig. 3 